\title{
WHEN DO MATCHED-MODEL AND HEDONIC TECHNIQUES YIELD SIMILAR PRICE MEASURES?
}

\author{
Ana Aizcorbe \\ Board of Governors of the Federal Reserve System \\ Carol Corrado \\ Board of Governors of the Federal Reserve System \\ Mark Doms \\ Federal Reserve Bank of San Franc isco
}

June 16, 2003

\begin{abstract}
Hedonic techniques were developed to control for quality differences across goods and over time in order to construct constant-quality aggregate price measures. When the available data are a panel of high-frequency data on models whose characteristics are constant over time, matched-model price indexes can also be used to obtain constantquality price measures. We show this by demonstrating that, given data of this type, certain matched-model indexes yield price measures that are numerically close to those obtained using hedonic techniques.
\end{abstract}

* This paper is a condensed version of a paper that was presented at the CRIW workshop on Price Measurement at the NBER Summer Institute, July 31-August 1, 2000 and is available at http://www.nber.org. For helpful comments, we thank Ernst Berndt, Jack Triplett, colleagues at the Board and participants of the CRIW workshop. The views expressed in this paper are those of the authors and do not necessarily reflect the views of the members of the Board of Governors or other members of the staff of Federal Reserve System 


\section{INTRODUCTION}

The literature on price and index number theory has generated two well-known approaches for obtaining aggregate measures of constant-quality price change: index numbers and hedonic techniques. ${ }^{1}$ The literature on price index numbers has compared different index number formulae and shown conditions under which superlative indexes provide better measures of price change than those provided by other formulas. ${ }^{2}$ The hedonic literature provides micro-theoretic support for the use of hedonic regressions to obtain price measures. $^{3}$

In practice, the choice of technique hinges importantly on the nature of the available data. Indeed, Griliches often said that "If you have the right kind of data, you don't need hedonics" and that "... what the hedonic approach attempted was to provide a tool for estimating 'missing' prices, prices of particular bundles not observed in the original or later periods" of an index. ${ }^{4}$ Hedonic techniques became the method of choice for measuring prices, especially for high-tech goods, in part, because the available data were rarely sufficiently rich for superlative indexes to adequately capture quality change. ${ }^{5}$ As time passed, however, the importance of data-quality issues in tipping the scales towards hedonic techniques was largely forgotten and the conventional wisdom became that hedonic techniques would always provide superior constant-quality price indexes.

As innovations that reduce the costs of compiling, storing and manipulating data increase the chances of finding the "right kind of data," it becomes increasingly important to understand the relative merits of the two approaches. Following closely the work of Berndt and Griliches (1993), this paper shows the conditions under which the two methods can yield numerically similar estimates. Specifically, we show that, under

1 Two relatively recent developments in this area are studies that use econometric estimates of demand systems to estimate welfare gains from the introduction of new products (e.g., Hausman (1999) and hedonic price measures that explicitly account for markets where consumers are heterogeneous and firms enjoy some degree of market power (e.g., Feenstra (1995), Berry, Levinson and Pakes (1995) and Pakes (2002).

2 See Diewert (1987) for a review of this literature.

3 See, for example, Triplett $(2003,1989$, and 1988) for reviews of this literature.

4 Ohta and Griliches (1976).

5. This view was fueled, in part, by a path-breaking paper by Dulberger (1989). Using a rich dataset, Dulberger generated both hedonic and matched-model indexes for computers - an industry characterized by rapid product innovation. She found that the price measures derived from the hedonic approach showed faster declines than those calculated from superlative indexes. The conclusion was that calculating superlative indexes could not control for quality change and, hence, showed slower price declines. This 
certain conditions, the dummy variable (DV) price measure obtained from a hedonic regression is numerically close to a chained, matched-model geometric mean price index. The required conditions are that the dataset be a panel of prices on models whose characteristics are constant over time--to allow the matching of most observations in the data--and that the observations be high frequency--to minimize the numerical influence of observations that cannot be matched (i.e., turnover observations). ${ }^{6}$

This correspondence of the two measures is also useful because there are still some quarters where price measures obtained from hedonic regressions are viewed with skepticism while those obtained from matched-model methods are not. Concern over the results from hedonic techniques arises for several reasons, including assumptions about functional form, how the sample of observations is drawn, and the transparency in which estimates are derived. ${ }^{7}$ Our demonstration that the two approaches are more like "cousins" lends support to measures constructed using hedonic techniques and provides a framework with which to assess any potential differences. ${ }^{8}$

We first use the framework in Berndt and Griliches (1993) to make this point algebraically, and then illustrate the major points using a panel dataset on Intel's microprocessors. ${ }^{9}$

issue bears revisiting now that available datasets are of higher quality.

6 It is important to note that, in our context, "matched model indexes" refers to the construction of price indexes using panel data and not methods used by statistical agencies to price missing items.

7 A recent appraisal of the methods used by BLS to contruct price measures was conducted by the National Academy (National Research Council(2002). In their recommendations, the Academy report cites skepticism as to the userfulness of the dummy variable method, citing parameter instability and other econometric issues as potential problems (P. 143, Recommendation 4-4).

8 The argument here is relevant for datasets where the only available information are prices and characteristics. If, in addition, one also has data on the quantities purchased, then one can construct a matched-model superlative index that is, in theory, superior to both the DV and geomean measures because it appropriately weights price change for each model. Although the theoretical superiority of superlative indexes is well known, the ability of superlative techniques to provide measures that are superior in practice depends, again, on the nature of the data. As discussed below, a straightforward extension of our argument to the Translog price index shows that if the data are such that most of the observations can be matched, and if the weight placed on turnover observations is small, then the superlative index measures are arguably superior to the other two.

9 Other studies have considered the similarities between hedonic and price index measures of price change: Triplett and MacDonald (1977) algebraically demonstrated that DV estimates from a semi-log hedonic regression can be interpreted as a ratio of geometric means of price levels that have been adjusted for quality change using the hedonic coefficients and used this result to apply a quality adjustment to the wholesale price index (WPI) that was then published by the BLS; Feenstra (1995) demonstrates that a DV measure obtained from a semi-log hedonic regression estimated using weighted least squares gives a fixedweighted index that has been adjusted for quality change; more recently, in a series of papers, Silver and Heravi $(2002,2003)$ have studied the algebraic similarities of alternative price measures. Specifically, they 


\section{Hedonics: The Dummy VARIAbLe Measure ${ }^{10}$}

The typical hedonic regression explains the prices of each variety or model of a good that is produced and sold at time $\mathrm{t}\left(\mathrm{P}_{\mathrm{m}, \mathrm{t}}, \mathrm{m}=1 \ldots \mathrm{M}\right)$ as a function of the quantities of its characteristics $\left(\mathrm{C}_{\mathrm{k}, \mathrm{m}, \mathrm{t}}, \mathrm{k}=1, \ldots \mathrm{K}\right)$ and time dummy variables $\left(\mathrm{D}_{\mathrm{m}, \mathrm{t}}, \mathrm{t}=1, \ldots \mathrm{T}\right)$. In semi-logarithmic form, this relationship is expressed as:

$$
\ln P_{m, t}=\sum_{k} \beta_{k} C_{k, m, t}+\sum_{t} \delta_{t} D_{m, t}+\varepsilon_{m, t}
$$

where $\quad \mathrm{D}_{\mathrm{m}, \mathrm{t}} \quad=1$ if a price for model $\mathrm{m}$ is observed at time $\mathrm{t}$, and $=0$ otherwise.

$\beta_{\mathrm{k}}$ and $\mathrm{d}_{\mathrm{t}}$ are econometric estimates and $\mathrm{e}_{\mathrm{m}, \mathrm{t}}$ is an error term. Each model has $\mathrm{K}$ characteristics that influence its value, and, in the general, the quantity of each characteristic in a model can change over time. The characteristics typically are numeric values (such as the speed, in number of megahertz, for a microprocessor), but they can also be dummy variables that designate the presence or absence of an attribute of the good in a particular model (such as extra cache memory).

Because the $\Sigma_{k} \beta_{k} C_{k, m, t}$ terms control for differences in each model's qualities, the regression delegates all other influences on prices to the time dummies and the residuals. ${ }^{11}$ The time dummy terms, $\Sigma_{\mathrm{t}} \mathrm{d}_{\mathrm{t}} \mathrm{D}_{\mathrm{m}, \mathrm{t}}$, capture the average value of the other influences, and the coefficients on the time dummies yield an estimate of the aggregate constant-quality price level for the good at time t. The dummy variable (DV) measure of price change is the difference between the estimated time dummy coefficients for time $\mathrm{t}$ and time $\mathrm{t}-1$. The difference can be expressed in terms of observed prices and estimated values for the characteristics. ${ }^{12}$

$$
\begin{array}{r}
\delta_{t}-\delta_{t-1}=\sum_{m \in M(t)}\left(\ln P_{m, t}-\sum_{k} \beta_{k} C_{k, m, t}\right) / M_{t}- \\
\sum_{m \in M(t-1)}\left(\ln P_{m, t-1}-\sum_{k} \beta_{k} C_{k, m, t-1}\right) / M_{t-1}
\end{array}
$$

show that the DV measure may be viewed as a special case of an exact price index. 10 See Berndt (1991) and Triplett (2003) for a full treatment of this hedonic measure. 11 Pakes (2002) discusses the interpretation of the coefficients in a hedonic regression.

12 The residuals have been suppressed because they do not play a critical role in our argument. 
where the notation $\Sigma_{\mathrm{m} \in \mathrm{M}(\mathrm{t})}$ denotes summation over models bought and sold at time $\mathrm{t}$, and the M's denote the total number of such models. Note, then, that the DV measure for price change from $\mathrm{t}-1$ to time $\mathrm{t}$ is the difference of two (logged) geometric means: the mean of quality-adjusted prices for models that exist at time t--the first term-and that of models that exist at time $\mathrm{t}-1$--the second term.

As seen in (2), the data requirements for this method are price and characteristics data for a set of goods, and this set can change over time. One may, therefore, use a stack of cross-sectional data in order to obtain constant-quality price measures. This is an important advantage of hedonic techniques over matched-model methods because, as discussed below, the use of matched-model methods requires that one be able to track identical goods over time--i.e., to have a panel dataset.

\section{A COMPARISON OF THE DV MEASURE WITH MATCHED-MODEL INDEXES}

If one has panel data and if the data are sufficiently granular that each model represents a homogeneous variety - in terms of the above notation, if $\mathrm{C}_{\mathrm{k}, \mathrm{m}, \mathrm{t}}=\mathrm{C}_{\mathrm{k}, \mathrm{m}, \mathrm{t}-\mathrm{l}}$ for all $\mathrm{t}$ - then a matched-model index could, under certain conditions, yield a price index that adequately controls for quality differences across models.

For each good, one must have a time series of observations over which the attributes of the good remain constant, a non-trivial requirement. In some industries, like housing or custom software, many of the goods that appear in the market at any given period are likely very different from those in the market in other periods, making it impossible to form a panel of homogeneous goods. However, to the extent that the industry under study allows one to observe data whose characteristics do not change over time, matched-model indexes may provide a useful alternative to hedonic measures. Their ability to do so hinges importantly on the number of turnover observations in the data.

To show this, we first demonstrate that the DV measure in (2) is a matched-model geometric mean when the data do not contain any turnover observations (i.e., when the panel is balanced). We then argue that the influence of turnover observations will likely be small in high-frequency datasets. 
In the absence of turnover, the summations in (2) are over the same models and may be combined: that is, the goods that exist at time $t$ are the same goods that exist at time $\mathrm{t}-1(\mathrm{M}(\mathrm{t})=\mathrm{M}(\mathrm{t}-1)$, denoted $\mathrm{M}(\mathrm{t}, \mathrm{t}-1)$. Moreover, the number of goods in each period are also equal: $\mathrm{M}_{\mathrm{t}}=\mathrm{M}_{\mathrm{t}-1}=\mathrm{M}$. Imposing these two restrictions, we can rewrite (2) as:

$$
\begin{aligned}
\delta_{t}-\delta_{t-1} & =\sum_{m \in M(t,-1)}\left(\ln P_{m, t}-\ln P_{m, t-1}\right) / M- \\
& \sum_{m \in M(t, t-1)}\left(\sum_{k} \beta_{k} C_{k, m, t}-\sum_{k} \beta_{k} C_{k, m, t-1}\right) / M
\end{aligned}
$$

where $\Sigma_{m \in M(t, t-1)}$ denotes a summation taken over goods "alive" in both time $\mathrm{t}$ and time $\mathrm{t}-1$.

The first term is a (logged) geometric mean of observed price relatives, while the second term captures the average change in the value of characteristics for goods. Then, if the observations are defined so that models are homogeneous over time, then, the second term vanishes (i.e., $\Sigma_{k} \beta_{k} C_{k, m, t}=\sum_{k} \beta_{k} C_{k, m, t-1}$ ) and the DV measure boils down to a (logged) geometric mean of price relatives:

$$
\delta_{t}-\delta_{t-1}=(1 / M) \sum_{m \in M(t, t-1)}\left(\ln P_{m, t}-\ln P_{m, t-1}\right)
$$

What happens when there exists product turnover? Consider the introduction of a new good (call it "N") at time t. ${ }^{13}$ The familiar problem for price indexes is that one cannot calculate a price relative for the new model in the period of introduction because a price for the previous period does not exist. From a theoretical point of view, the appropriate price to use in the period before introduction is the Hicksian reservation price that drives demand to zero. ${ }^{14}$

In practice, the two methods have different ways to deal with this issue. A DV price measure provides an explicit imputation for these missing prices. To see this, take the general expression for the DV measure in (2) and split out terms associated with the new good from those of continuing goods. After some tedious algebra, the DV estimate for price change from over $\mathrm{t}, \mathrm{t}-1$ can be expressed as:

13 Although we only show this for the case of an entering model, the same holds true for an exiting model. 


$$
\begin{aligned}
\delta_{t}-\delta_{t-1} & =\left(M_{t-1} / M_{t}\right)\left[\sum_{m \in M(t, t-1)}\left(\ln P_{m, t}-\ln P_{m, t-1}\right) / M_{t-1}\right] \\
& +\left(1 / M_{t}\right)\left[\left(\ln P_{N, t}-\sum_{k} \beta_{k} C_{N, k, t}\right)-\sum_{m \in M(t-1)}\left(\ln P_{m, t-1}-\sum_{k} \beta_{k} C_{k, m, t-1}\right) / M_{t-1}\right]
\end{aligned}
$$

Equation (5) shows that in the presence of turnover, the DV measure may be written as a weighted average of a price measure for continuing goods--the first term-and one for the turnover goods--the second term--where the weights are the share of observations of each type. For continuing goods, the DV measure is just a geometric mean of price relatives in logged form. We call this a "matched-model" geometric mean (geomean, for short) to indicate that the mean is taken only over observations that exist in both periods. For the turnover good, the hedonic regression imputes a price relative as the difference between the quality-adjusted price for the new variety at time $t$ $\left(\ln \mathrm{P}_{\mathrm{N}, t}-\sum_{\mathrm{k}} \beta_{\mathrm{k}} \mathrm{C}_{\mathrm{N}, \mathrm{k}, \mathrm{t}}\right)$ and the average quality-adjusted price for all observed models in the prior period $\left(\Sigma_{\mathrm{m} \in \mathrm{t}-1}\left(\ln \mathrm{P}_{\mathrm{m}, \mathrm{t}-1}-\Sigma_{\mathrm{k}} \beta_{\mathrm{k}} \mathrm{C}_{\mathrm{k}, \mathrm{m}, \mathrm{t}-1}\right) / \mathrm{M}_{\mathrm{t}-1}\right)$.

In contrast, index number methods are silent on how to handle the missing prices associated with new and exiting goods. Instead, one common practice is to form a matched-model index that includes price relatives only for continuing goods. ${ }^{15}$ Implicit in this approach is the assumption that a price index calculated over continuing goods is a good proxy for the theoretically-correct price relative for the turnover good.

It is not at all clear which, if either, of these imputations corresponds to the theoretically-correct Hicksian price. However, in practice, both aggregate price measures are heavily influenced by the price movement in the continuing goods. In (5), if the number of turnover observations is small relative to all observations, then the imputed price relative for the new good will receive a small weight and the DV measure will be largely driven by the geomean of continuing goods. When the dataset contains highfrequency observations, any given time period is unlikely to contain many turnover observations. If so, then the weight placed on the implicit imputation for price change in the turnover goods will be numerically small and the two indexes will yield numerically similar measures.

14 Hicks (1940). 
There is an analogous correspondence for the Tornquist index for the case when the associated quantities are also observed. In the absence of turnover, a hedonic regression that is 1) specified in first-differenced form with 2) the dependent variable multiplied by tornquist revenue shares yields a DV measure of price change that is identical to the Tornquist index. As is the case with the geomean, the treatment of turnover differs in the two methods, but numerical differences will depend on the weight given to turnover observations. That weight is likely to be small in high-frequency datasets.

\section{EMPIRICAL ILLUSTRATION}

Illustrating the points made in the previous section, we calculate a variety of price indexes for Intel microprocessors (MPUs). The data are quarterly for 44 distinct MPUs used in desktop computers from 1993-99 - Each MPU in our dataset is a physically distinct device whose characteristics are constant over time: the MPUs differ by speed (measured in $\mathrm{MHz}$ ) as well as other characteristics that do not change over the life of the chip (cache memory capacity, for example). ${ }^{16}$

As noted above, differences between the matched-model and DV measures can arise when there are turnover observations. The importance of entry and exit for our data are presented in table 1. First, note that the number of periods that involve some type of turnover is small in these data. There are never more than 6 chips introduced in any given quarter and never more than 4 retired. This suggests that a DV measure from a regression like (1) will be numerically close to a matched-model geomean calculated from the same data.

In terms of revenue shares, the quarterly revenue shares of each of the entering and exiting microprocessors in their introductory and retirement periods are mixed; they are always less than 25 percent but, excluding a few outliers, tend to be less than 10 percent. This suggests that a DV measure from a fixed-effect regression where the dependent variable is pre-multiplied by Tornquist weights will be numerically close to a matched-model Tornquist index.

15 We do not address the "imputation method" because it requires an estimated hedonic regression. 16 These data are described in more detail in Aizcorbe, Corrado, and Doms (2000). 
The relatively low turnover from a revenue point of view may in itself be surprising and interesting. The common notion for high-tech goods is that product turnover is rampant, making the linking of products from one period to another difficult. However, for Intel MPUs and personal computers, much of the market in a given quarter is comprised of products that existed in the previous period. When new products are introduced, they tend to have very small market shares. There is a similar case for products that exit: exiting products tend to have very small market shares.

Finally note that if the data were of lower frequency--say, annual-then product turnover would be much greater. In that case, the omission of turnover observations to form matched-model indexes would be more likely to generate larger differences between the matched-model and hedonic price measures.

We estimate two hedonic regressions, both specified in semi-log form (as in (1)). Because models' characteristics are constant over time in our dataset--so that $\mathrm{C}_{\mathrm{k}, \mathrm{m}, \mathrm{t}}=$ $\mathrm{C}_{\mathrm{k}, \mathrm{m}, \mathrm{t}-1}=\mathrm{C}_{\mathrm{k}, \mathrm{m}}$ for all t--both specifications are special cases of (1'):

$$
\ln P_{m, t}=\sum_{k} \beta_{k} C_{k, m}+\sum_{t} \delta_{t} D_{m, t}+\varepsilon_{m, t}
$$

The first specification controls for quality differences across models with the use of fixed effects. That is, we assume $\Sigma_{\mathrm{k}} \beta_{\mathrm{k}} \mathrm{C}_{\mathrm{k}, \mathrm{m}}=\beta_{\mathrm{m}}$ and rewrite (1') as:

$$
\ln P_{m, t}=\beta_{m}+\sum_{t} \delta_{t} D_{m, t}+\varepsilon_{m, t}
$$

The second specification uses a more conventional functional form. This specification—done for illustrative purposes only—posits that (logged) prices are a quadratic function of speed: that is, $\Sigma_{k} \beta_{k} C_{k, m}=a+b\left(\operatorname{speed}_{m}\right)+c\left(\operatorname{speed}_{m}\right)^{2}$ and (1') becomes:

$$
\ln P_{m, t}=\mathrm{a}+\mathrm{b}\left(\operatorname{speed}_{\mathrm{m}}\right)+\mathrm{c}\left(\operatorname{speed}_{m}\right)^{2}+\sum_{t} \delta_{t} D_{m, t}+\varepsilon_{m, t}
$$


The fixed-effect regression has several advantages over a more conventional specification (as in (7)). First, the fixed-effect regression is more flexible-it does not impose a particular functional form-like the quadratic. The fixed-effect model also does not place any restrictions across models whereas (7) requires that the relationship between speed and price be the same across models. Third, one doesn't need to choose characteristics and use them directly in the fixed-effect regression. The characteristics are only used to define models such that any observed characteristics are unchanged over time. Finally, the fixed-effect specification can provide more stable DV measures than the more-conventional specification (see Aizcorbe (2003)).

Table 2 reports the resulting DV measures from these regressions alongside matched-model indexes. The first two columns compare a matched-model geomean index (column 1) and the DV price measure from the fixed-effect regression. Consistent with the arguments made earlier, the two measures are identical in the five time periods where there was no turnover: 93:3, 93:4, 94:2, 94:3, and 97:1. Although the two measures can diverge substantially in other time periods, their average rates for 1993-99 are remarkably similar (-52.5 vs. -53.0). Similar results were reported in Aizcorbe, Corrado and Doms (2000) for personal computers. Silver and Heravi $(2001,2002)$ report similar findings using scanner data for washing machines and televisions.

In contrast, the average rate for the DV measures from the usual specification is noticeably slower than those of the geomean or the fixed-effect regression (-48.1). Because the two regressions were done using the same data, we attribute these differences to econometric problems - misspecification, collinearity, etc. - in the usual specification.

Finally, the last two columns show two matched-model superlative indexes: a Tornquist and a Fisher Ideal index. Consistent with findings elsewhere in the literature, the two measures give quite similar results both in each period and overall. The superlative price indexes fall faster than either the geomean or hedonic indexes. We attribute those differences to the fact that both the geomean and hedonic specifications impose constraints on the substitution possibilities while the superlative indexes do not. That the superlative indexes show faster price declines suggests some degree of substitution across chips. 


\section{CONCLUSION AND CAVEATS}

As sources of detailed data become increasingly available, matched-model indexes become a viable method for constructing constant-quality price measures. In particular, when very disaggregate panel data on prices are available at a high frequency, and when the data display only a small amount of turnover at any given point in time, the DV measure of price change from a hedonic regression will be numerically similar to the price measure obtained from a matched-model geomean. We illustrate this point using data for Intel's microprocessors, a segment of the semiconductor market that is characterized by rapid product innovation. Even so, the data are of sufficiently high frequency that the influence of these turnover observations is relatively small and the two indexes display nearly identical rates of price change.

We hasten to add that construction of the matched-model indexes is not always

possible. That depends on both the nature of the goods in the industry under study and on the availability of the needed data. 


\section{BIBLIOGRAPHY}

Aizcorbe, Ana M. (2003) "The Stability of Dummy Variable Price Measures Obtained from Hedonic Regressions," FEDS Working paper No. 2003-5, February. Available at http://www.rsma.frb.gov/wpapers/feds/2003/200305/200305abs.html

Aizcorbe, Ana M., Carol Corrado and Mark Doms (2000) "Constructing Price and Quantity Indexes for High Technology Goods," Paper presented at the CRIW workshop on Price Measurement at the NBER Summer Institute, July 31-August 1. Available at http://www.nber.org/ confer/2000/si2000/doms.pdf

Berndt, Ernst R. (1991) The Practice of Econometrics: Classic and Contemporary. Reading, MA: Addison-Wesley Pub. Co.

Berndt, Ernst R., and Zvi Griliches (1993) "Price Indexes for Microcomputers: An Exploratory Study," in Price Measurements and Their Uses, ed. Murray Foss, Marilyn Manser, and Allan Young. (Chicago: The University of Chicago Press, 1993), pp. 63-93.

Berry, S., J. Levinsohn, and A. Pakes (1995) "Automobile Prices in Market Equilibrium," Econometrica, Pp. 841-890, July.

Diewert, W.E. (2001) "Hedonic Regressions: A Consumer Theory Approach," in Scanner Data and Price Indexes eds., R. Freenstra and M. Shapiro. Chicago, Ill.: University of Chicago Press. Available at: http://www.nber.org/books/criw00/diewert11-13-01.pdf

Dulberger, Ellen R. (1989) "The Application of a Hedonic Model to a Quality-Adjusted Price Index for Computer Processors," in Technology and Capital Formation, ed. Dale W. Jorgenson and Ralph Landau. Cambridge, Mass: MIT Press.

Feenstra, Robert C. (1995) "Exact Hedonic Price Indexes," Review of Economics and Statistics 77:634-654.

Hausman, Jerry (1999) "Cellular Telephone, New Products, and the CPI," Journal of Business and Economic Statistics 17 (April): 188-194.

Hicks, J.R.(1940) "The Valuation of Social Income, " Economica, 7:105-140.

National Research Council (2002) At What Price? Conceptualizing and Measuring Costof-Living and Price Indexes. Panel on Conceptual, Measurement, and Other Statistical Issues in Developing Cost-of-Living Indexes, Charles S. Schultze and Christopher Mackie, Editors. Committee on National Statistics, Division of Behavioral and Social Sciences and Education. Washington, D.C., National Academy Press. 
Ohta, M. and Z. Griliches (1976) "Automobile Prices Revisited: Extensions of the Hedonic Hypothesis." In Household Production and Consumption, ed. N. Terleckyj. NBER Studies in Income and Wealth, vol. 40. New York: Columbia University Press.

Pakes, Ariel (2002) "A Reconsideration of Hedonic Price Indices with an Application to PCs," Paper presented at Brookings' Workshop Hedonic Price Indices: Too Fast, Too Slow, or Just Right? Washington, D.C.

Silver, Mick and Saeed Heravi (2003), "Measurement of Quality-Adjusted Price Changes," ," in Scanner Data and Price Indexes eds., R. Freenstra and M. Shapiro. Chicago, Ill.: University of Chicago Press. Available at: http://www.nber.org/books/criw00/silver-heravi11-12-01.pdf

(2002), "Why the CPI Matched Models Method May Fail Us: Results From an Hedonic and Matched Experiment Using Scanner Data," Paper presented at Brookings Workshop "Hedonic Price Indexes: Too Fast, Too Slow, or Just Right?" Washington, DC February 1, 2002. Available at http://www.brook.edu/es/research/projects/productivity/workshops/20020201_silver.pdf

Triplett, Jack E. (2003) "Handbook on Quality Adjustment of Price Indexes for Information and Communication Technology Products," OECD Directorate for Science, Technology and Industry, Draft, OECD, Paris.

Triplett, Jack E. (1989) "Price and Technological Change in a Capital Good: A Survey of Research on Computers," in Technology and Capital Formation, ed. Dale W. Jorgenson and Ralph Landau. Cambridge, Mass: MIT Press.

Triplett, Jack E. (1988) "Hedonic Functions and Hedonic Indices, in The New Palgraves Dictionary of Economics, Pp. 630-34.

Triplett, Jack E. and Richard J. McDonald (1977) “Assessing the Quality Error in Output Measures: The Case of Refrigerators." The Review of Income and Wealth 23(2): 137-56. 
Table 1. Entry and Exit Shares for Intel Desktop CPUs

\begin{tabular}{|c|c|c|c|c|c|c|c|}
\hline & \multicolumn{3}{|c|}{ Entering devices $(\mathrm{t})$} & \multicolumn{3}{|c|}{ Exiting devices $(\mathrm{t}-1)$} & \multirow[b]{2}{*}{$\begin{array}{c}\text { Net Entry } \\
\text { Share (percent) } \\
(7)\end{array}$} \\
\hline & $\begin{array}{l}\text { Revenue Share } \\
\text { (percent) } \\
(1)\end{array}$ & $\begin{array}{c}\text { Number } \\
\text { (2) }\end{array}$ & $\begin{array}{c}\text { Observation } \\
\text { Share (percent) } \\
\text { (3) }\end{array}$ & $\begin{array}{c}\text { Revenue Share } \\
\text { Share (percent) } \\
\text { (4) }\end{array}$ & $\begin{array}{c}\text { Number } \\
\text { (5) }\end{array}$ & $\begin{array}{c}\text { Observation } \\
\text { Share (percent) } \\
(6)\end{array}$ & \\
\hline$\overline{93 Q 2}$ & 2.1 & 2 & 28.6 & 0.0 & 0 & 0.0 & 2.1 \\
\hline 93Q3 & 0.0 & 0 & 0.0 & 0.0 & 0 & 0.0 & 0.0 \\
\hline 93Q4 & 0.0 & 0 & 0.0 & 0.0 & 0 & 0.0 & 0.0 \\
\hline 94Q1 & 5.3 & 5 & 41.7 & 0.0 & 0 & 0.0 & 5.3 \\
\hline 94Q2 & 0.0 & 0 & 0.0 & 0.0 & 0 & 0.0 & 0.0 \\
\hline 94Q3 & 0.0 & 0 & 0.0 & 0.0 & 0 & 0.0 & 0.0 \\
\hline 94Q4 & 8.1 & 1 & 7.7 & 0.0 & 0 & 0.0 & 8.1 \\
\hline 95Q1 & 2.2 & 1 & 7.7 & 0.4 & 1 & 7.7 & 1.8 \\
\hline 95Q2 & 5.3 & 1 & 8.3 & 0.4 & 1 & 7.7 & 4.9 \\
\hline 95Q3 & 0.0 & 0 & 0.0 & 1.4 & 1 & 8.3 & -1.4 \\
\hline 95Q4 & 16.4 & 6 & 40.0 & 4.0 & 2 & 18.2 & 12.4 \\
\hline 96Q1 & 3.0 & 1 & 7.7 & 0.9 & 3 & 20.0 & 2.1 \\
\hline 96Q4 & 13.8 & 2 & 15.4 & 0.8 & 2 & 15.4 & 13.0 \\
\hline 97Q1 & 0.0 & 0 & 0.0 & 0.6 & 2 & 15.4 & -0.6 \\
\hline 97Q2 & 9.7 & 2 & 18.2 & 0.0 & 1 & 9.1 & 9.7 \\
\hline 97Q3 & 8.5 & 1 & 9.1 & 0.0 & 0 & 0.0 & 8.5 \\
\hline 97Q4 & 13.0 & 2 & 18.2 & 1.8 & 4 & 30.8 & 11.2 \\
\hline 98Q1 & 5.1 & 2 & 20.0 & 4.1 & 3 & 27.3 & 1.0 \\
\hline 98Q2 & 2.9 & 2 & 16.7 & 0.0 & 0 & 0.0 & 2.9 \\
\hline 98Q3 & 9.5 & 3 & 21.4 & 2.0 & 1 & 8.3 & 7.5 \\
\hline 98Q4 & 8.3 & 1 & 8.3 & 2.1 & 3 & 21.4 & 6.2 \\
\hline 99Q1 & 24.4 & 4 & 30.8 & 6.7 & 3 & 25.0 & 17.7 \\
\hline 99Q2 & 8.6 & 2 & 13.3 & 0.0 & 0 & 0.0 & 8.6 \\
\hline 93-99 & 5.8 & & 12.5 & 1.1 & & 8.9 & 4.7 \\
\hline
\end{tabular}

Source: Authors calculations based on proprietary data from Micro Design Resources. 
Table 2. Price Measures for Intel's Computational Microprocessors (quarterly percent change)

\begin{tabular}{|c|c|c|c|c|c|}
\hline \multirow[b]{2}{*}{ Date } & \multirow{2}{*}{$\begin{array}{c}\text { Geomean } \\
\text { Index }\end{array}$} & \multicolumn{2}{|c|}{ Hedonic Indexes } & \multicolumn{2}{|c|}{ Superlative Indexes } \\
\hline & & $\begin{array}{l}\text { Fixed- } \\
\text { Effects } \\
\end{array}$ & $\begin{array}{l}\text { Usual } \\
\text { Spec. }\end{array}$ & Tornquist & Fisher \\
\hline $93: 1$ & --- & --- & --- & --- & --- \\
\hline $93: 2$ & -5.21 & -8.52 & -5.87 & -3.80 & -3.80 \\
\hline $93: 3$ & -5.87 & -5.87 & -5.86 & -5.53 & -5.53 \\
\hline $93: 4$ & -12.78 & -12.78 & -12.78 & -11.99 & -11.99 \\
\hline $94: 1$ & -4.19 & -6.06 & -12.08 & -5.65 & -5.65 \\
\hline $94: 2$ & -9.87 & -9.87 & -9.87 & -10.19 & -10.18 \\
\hline $94: 3$ & -13.97 & -13.97 & -13.97 & -16.50 & -16.45 \\
\hline $94: 4$ & -17.94 & -18.44 & -16.86 & -20.70 & -20.60 \\
\hline $95: 1$ & -30.94 & -29.26 & -27.93 & -27.85 & -27.84 \\
\hline $95: 2$ & -12.55 & -12.49 & -10.98 & -13.27 & -13.15 \\
\hline $95: 3$ & -20.83 & -24.33 & -24.73 & -25.69 & -25.75 \\
\hline $95: 4$ & -21.89 & -19.76 & -9.73 & -25.64 & -25.63 \\
\hline $96: 1$ & -22.16 & -24.81 & -12.83 & -25.85 & -25.93 \\
\hline $96: 2$ & -27.22 & -29.73 & -28.79 & -27.44 & -27.46 \\
\hline $96: 3$ & -20.49 & -20.23 & -20.41 & -22.84 & -22.86 \\
\hline $96: 4$ & -8.96 & -7.76 & -7.41 & -12.85 & -12.87 \\
\hline $97: 1$ & -8.75 & -8.75 & -8.75 & -11.97 & -11.92 \\
\hline $97: 2$ & -12.01 & -15.98 & -1.35 & -14.85 & -14.79 \\
\hline $97: 3$ & -21.35 & -18.63 & -15.41 & -28.54 & -28.52 \\
\hline $97: 4$ & -22.84 & -22.97 & -21.47 & -28.28 & -28.30 \\
\hline $98: 1$ & -26.61 & -27.49 & -23.42 & -27.91 & -27.62 \\
\hline $98: 2$ & -23.37 & -19.15 & -15.99 & -31.33 & -31.43 \\
\hline $98: 3$ & -28.35 & -27.31 & -28.81 & -33.05 & -32.98 \\
\hline $98: 4$ & -14.89 & -11.87 & -8.58 & -28.03 & -28.11 \\
\hline 99:1 & -24.02 & -23.08 & -29.50 & -21.45 & -21.21 \\
\hline $99: 2$ & -24.87 & -29.83 & -28.95 & -25.48 & -25.25 \\
\hline $99: 3$ & -22.00 & -21.10 & -14.68 & -29.93 & -29.98 \\
\hline $99: 4$ & -21.97 & -21.57 & -22.79 & -29.59 & -29.52 \\
\hline 93-99 & -18.00 & -18.21 & -16.29 & -20.97 & -20.94 \\
\hline
\end{tabular}

Source: Authors' calculations based on proprietary data from MicroDesign Resources. 